\title{
Farewell editorial
}

\author{
Carlos Closa
}

After six years as co-editor, the 2021 volume closes my tenure at the EPSR. I depart with a sense of satisfaction: in 2020, the journal climbed into the top quartile of the SSCI political science rankings, and we saw record submission numbers for the second year in a row. The journal has also implemented a policy of gender parity in its editorial board and reviewed gender balance in both submissions and publications. ${ }^{1}$ Editing the journal has been a highly rewarding and enjoyable experience that has also served as a learning one. From the process of reading and revising hundreds of manuscripts and reviewers' reports (I am still impressed by their excellent quality!), my own knowledge of contemporary research practices has been significantly enhanced and, I dare to say, I have improved as a researcher as a result.

The journal has also provided an excellent platform from which to observe the broader trends in political science and to see how these have aligned with the mission and vision that I have set for the journal together with my co-editors, Wil Hout and Matt Qvortrup. Our two most important decisions related to the profile of the journal and the nature of our publication output. Regarding the profile of EPSR, we opted for a pluralistic approach both in terms of sub-disciplines and methods. We aimed to publish widely, from political theory to international relations and from public policy to comparative politics. We also wanted to be inclusive of the diverse range of methodologies that are used in political science. In doing so, our intention was to represent fairly the state of the discipline. Our second major decision was our choice not to publish special issues, commissioned papers, or review articles, keeping all four issues in each volume completely open for the very best of the stand-alone research articles that we received. Those two decisions placed a good deal of expectation on the supply side of the publishing process and, on reflection, the results to date have been mixed. This is especially the case when measured by plurality, with several sub-disciplines still under-represented among our published articles.

We have nevertheless published a good deal of top quality research with great methodological and, often, theoretical sophistication. However, using the vantage point that the journal provides, I have been able to identify some trends in political science that have left me with a sense of dismay. Rather than discussing political issues that are crucial to people's lives, political science seems increasingly dominated by publication-oriented research, where the presentation of results obtained through the application of ever more sophisticated methodologies to existing data sets has become the norm. Data production seems to have become less important, due also to the twin concerns of cost and the need for rapid publication for career purposes. There seems to have been a similar decline in theoretical contributions. Unsurprisingly, studies in areas in which there is a large supply of data suitable for analysis via statistical inference have dominated the EPSR's published output. Recently, the editors of our sister journal, the APSR, argued that we have arrived at a point where our research questions are directed by data and methods, and they concluded with a

\footnotetext{
${ }^{1}$ Closa, C.; Catherine Moury, Zuzana Novakova, Matt Qvortrup and Beatriz Ribeiro (2020) Mind the (submission) gap: EPSR gender data and female authors publishing perceptions European Political Science, 19(3), 428-442 (Q3 JCR) https://doi. org/10.1057/s41304-020-00250-5 
plea for engaging in topical and crucial questions. ${ }^{2}$ I could not agree more with this call for a more engaged political science.

To some, this reflection may read like a mechanical validation of the standards of any research arising from non-quantitative traditions on the assumption that they deal with 'real' political issues. Not at all. In fact, I have been surprised by the recurrent lack of rigour displayed in non-quantitative disciplines when it comes to presenting research designs, describing procedures and techniques for data generation and analysis, and methodological discussion. This concern led me to publish a paper in another ECPR journal, European Political Science, ${ }^{3}$ in which I suggested that researchers working within interpretative traditions should strive to strengthen qualitative research transparency by being more explicit about the planning, implementing, and reporting of their work. Those of us within these traditions cannot assume that our self-declared focus on important/topical issues can be used to justify our relative lack of methodological sophistication. In an era in which information and communication channels abound, opinions and even fake news can be portrayed as scientific research. The growth of alternative, often unreliable, sources of information creates a challenge for the credibility of research findings, and the application of better standards for reporting how we know what we know, and whether and how our insights apply more widely, can only serve to enhance our credibility. Without falling into a radical pro-causality model of political science, qualitative research can significantly improve in terms of transparency and data access. Under my co-editorship, the journal implemented a soft version of Data Access and Research Transparency (DA-RT) statement, acknowledging that while political science must move inexorably in that direction of ever-greater transparency, non-experimental and non-statistically based research cannot be expected to mechanically adopt the standards of experimental and statistics-based research.

My sense is that I will leave behind a very robust journal, with a solid reputation and a consolidated team. I must thank Simona Piattoni, the former Chair of the ECPR, for her confidence in me and the ECPR Publications sub-committee for their engagement. My thanks also go to Rebecca Gethen and the rest of the staff at the ECPR for their continuous support and to David Mainwaring from CUP for his dedicated attention to the journal. Much of the success of this period is due to the wonderful team that worked with me during these years: Wil Hout and Matt Qvortrup as co-editors, Karim Knio and Catherine Moury as associated editors, and Zuzana Novakova as assistant editor for the whole period. Thank you all for this great experience.

\footnotetext{
${ }^{2}$ Editors (2020) Notes from the Editors American Political Science Review (2020) 114, 4, v-vii doi:10.1017/ S000305542000074X

${ }^{3}$ Closa, C. Planning, implementing and reporting: increasing transparency, replicability and credibility in qualitative political science research European Political Science https://doi.org/10.1057/s41304020002992
}

Cite this article: Closa C (2021). Farewell editorial. European Political Science Review 13, 1-2. https://doi.org/10.1017/ S1755773920000417 